Research Article

\title{
Biocomposites Developed with Litchi Peel Based on Epoxy Resin: Mechanical Properties and Flame Retardant
}

\author{
Tuan Anh Nguyen \\ Faculty of Chemical Technology, Hanoi University of Industry (HaUI), No. 298, Cau Dien Street, Bac Tu Liem District, \\ Hanoi 100000, Vietnam \\ Correspondence should be addressed to Tuan Anh Nguyen; anhnt@haui.edu.vn
}

Received 23 June 2021; Accepted 18 August 2021; Published 31 August 2021

Academic Editor: Ajaya Kumar Singh

Copyright ( 2021 Tuan Anh Nguyen. This is an open access article distributed under the Creative Commons Attribution License, which permits unrestricted use, distribution, and reproduction in any medium, provided the original work is properly cited.

Bio-based composites are reinforced polymeric materials, which include one or two bio-based components. Biocomposites have recently attracted great attention for applications ranging from home appliances to the automotive industry. The outstanding advantages are low cost, biodegradability, lightness, availability, and solving environmental problems. In recent days, biodegradable natural fibers are attracting a great deal of interest from researchers to work on and develop a new type of composite material for diverse applications. The objective of this work is to evaluate fire resistance and mechanical properties of epoxy polymer composites reinforced with lychee peel (Vietnam), at $10 \mathrm{wt} \%, 20 \mathrm{wt} \%$, and $30 \mathrm{wt} \%$ mass $\%$. The study showed that the mechanical properties and flame retardancy tended to increase in the presence of lychee peel reinforcement. In the combined ratios, $20 \mathrm{wt} \%$ lychee rind gave a limiting oxygen index of $21.5 \%$, with a burning rate of $23.45 \mathrm{~mm} / \mathrm{min}$. In terms of mechanical strength, in which the Izod impact strength increased by $26.46 \%$, the compressive strength increased by $25.20 \%$ and the tensile strength increased by $20.62 \%$. The microscopic images (SEM images) show that the particle distribution is quite good and the adhesion and wetting compatibility on the two-phase interface of lychee peel-epoxy resin are strong.

\section{Introduction}

Currently, the world is facing a lot of problems related to waste management. Particularly, organic recycling waste or rational use of waste is a primary concern. Sources of waste are medical waste, organic waste, and plastic waste. Of these three categories, organic waste is produced in abundance around the world. The organic waste includes kitchen waste such as vegetable peels, fruits, leaves, eggshells, green stalks, and vegetables in a chopped state. Many of these have biodegradable properties [1]. The study of mechanical properties of fiber-reinforced composites is of great interest to many scientists. Biodegradable organic wastes such as lemon peels, onion peels, and potato and carrot peels have recently been studied to make environmentally friendly, biodegradable composites. Green composites were developed using various fillers such as the outermost peel of a lemon [1], onion, potato, and carrot [2], and cellulose and silk fibroin [3] have recently been studied for their production of environmentally friendly, biodegradable composite materials. In addition, banana fibers and eggshells are used as fillers to make biomaterials for concrete reinforcement, obtained from agricultural and postconsumer wastes [4]. Furthermore, chicken femur and beak and fish bones were used to make adsorbents to reduce $\mathrm{Cd}^{2+}$ from aqueous media [5]. Antonio Mancino et al. have studied using sisal fibers to reinforce epoxy-based composites (green), and the results show that the mechanical properties are improved (allowing the tensile strength to increase by 28\%; the fibers are randomly improved) [6]. Used coffee grounds are a biodegradable organic waste that has been studied by $\mathrm{Li}$ et al. [7]. In the work, the research has been carried out to reduce the brown color of used coffee grounds and strengthen polylactic acid (PLA) composites. Mohammad Saberian and colleagues also did an overview of the recycling of used coffee grounds, oriented to the application as a building material [8]. Parbin et al. evaluated the mechanical properties of natural fiber-reinforced epoxy composites, concluding that fibers of natural origin such as plant fiber and animal fiber have very 
good compatibility with epoxy resin. It can be concluded from this review that natural fibers are very compatible with epoxy substrates because both fibers and matrix adhere to each other very well forming a strong bond between them. They have the potential to replace synthetic fibers in the world of composite manufacturing because they exhibit the same or better physics and mechanical properties in many cases [9]. Natural fibercontaining epoxy composites have great potential for engineering applications due to their environmental suitability and technical and economic feasibility. Many efforts have been done in this direction to create these relatively new composites. To improve compatibility, the researchers used different methods, such as treating natural fibers with $\mathrm{NaOH}$, silane, and ultrasonic. However, alkali treatment is the most widely used and is believed to be the technique to enhance substrate compatibility and improve composite properties [10]. TorresArellano et al. have studied the incorporation of natural fibers such as Henequen, Ixtle, and Jute into biobased epoxy resins. Mauricio Torres-Arellano and colleagues have studied the application of natural fibers such as Henequen, Ixtle, and Jute into biobased epoxy resins. The results show that the Jute fiber reinforcement provides high stiffness and strength while the Henequen fiber shows a high strain value [11]. Ayyappa Atmakuri et al. studied the mechanical properties and wetting ability of hybrid epoxy composites reinforced with hemp/flax fiber and banana/pineapple fiber. The results of the work show that hemp and flax fibers are a potential alternative to reinforcements in composites. Hemp and flax fibers can be used for structural applications [12]. Rajeshkumar et al. studied improving the mechanical properties of epoxy resins reinforced with natural fibers (Phoenix sp.). In this experiment, the effects of reinforced content $(0 \%, 10 \%, 20 \%, 30 \%, 40 \%$, and $50 \%$ by volume) and material form (bead $(300 \mathrm{~mm})$ and thread $(10 \mathrm{~mm}, 20 \mathrm{~mm}$ and $30 \mathrm{~mm})$ ) were evaluated. The $40 \%$ volume fraction of the $20 \mathrm{~mm}$ long fiber represents a good compromise to obtain a good quality composite [13]. Research on reinforcement for green composites, such as cellulose fiber with abundant supply, is a modern approach. Look specifically for cellulose fibers that are produced by natural pathways such as silk or by biological pathways. The structure of the yarn is preserved, and the yarn has many special properties, including bacterial cellulose fibers. Bacterial cellulose $(\mathrm{BC})$ fibers with purity, purity, and high content have been noticed by many scientists [14-18]. Epoxy is widely used with good mechanical properties and high compatibility with reinforcing materials of natural origin selected for the manufacture of synthetic materials with natural fiber reinforcement. However, the disadvantage of epoxy resin is its brittleness. Therefore, in order to improve this property, there are many works that have been studied to strengthen it with different materials such as glass fiber, natural fiber, carbon fabric, and nanoadditives (nanoclay [19] and multiwalled carbon nanotubes [20, 21]) and hybridize them with fly ash fillers [22-25], epoxidized linseed oil [26], and so on. Green composite materials are receiving much research attention and have an important role and position in the world of materials science and engineering today because the increasing demand of environmentally friendly materials more and more reduces environmental degradation, reduces pollution, and saves the Earth. Furthermore, the reuse of wastes from the agricultural and food industries as reinforcing materials or additives for composites is a preferred research direction. Natural fiber composites also help rural economic development [27]. In this work, the effects of natural fibers obtained from organic waste (lychee peels) were studied, and the morphological structure, mechanical properties, and flame retardancy were evaluated. The focus of this work is on the use of agricultural waste, lychee peel, as reinforcement for epoxy composite materials at the following concentrations: $0 \mathrm{wt} \%, 10 \mathrm{wt} \%, 20$ $\mathrm{wt} \%$, and $30 \mathrm{wt} \%$.

\section{Materials and Methods}

2.1. Materials. Epikote 240 epoxy (E 240) derived from bisphenol $\mathrm{F}$ was purchased from Shell Chemicals (USA) with $24.6 \%$ epoxy content, epoxy equivalent of $185-196$, and viscosity at $250 \mathrm{C}$ in the range of $0,7 \div 1,1$ Pa.s. Diethylene triamin (DETA) was purchased from Sigma-Aldrich. Chemical formula of DETA is $\mathrm{H}^{2} \mathrm{~N}\left(\mathrm{CH}^{2}\right) \mathrm{NH}\left(\mathrm{CH}^{2}\right)^{2} \mathrm{NH}^{2}$ with molar weight of 103 g.mol-1, and specific gravity at $25^{\circ} \mathrm{C}$ of $0.95 \mathrm{~g} / \mathrm{cm} 3$. Litchi (Litchi Chinensis) peel was supplied form Thanh Ha district, Hai Dương province, Vietnam. $\mathrm{NaOH}$ was purchased form Sigma-Aldrich, Vietnam.

\subsection{Methods}

2.2.1. Sample Preparation. Litchi peel (LP) is peeled from lychee fruit and dried in the sun for 7 days to remove moisture. The dried pods are ground into a powder. To achieve uniform particle size, the sieving method is used. The material was then washed with distilled water several times and immersed in 5\% $\mathrm{NaOH}$ solution for $3 \mathrm{~h}$ at room temperature. The beads were further washed with distilled water to remove $\mathrm{NaOH}$. Continue drying at 50 degrees Celsius for 24 hours until dry. Biosynthetic materials were fabricated with litchi peel (LP) content: $10 \mathrm{wt} \%$, $20 \mathrm{wt} \%$, and $30 \mathrm{wt} \%$ (see Figure 1).

\subsubsection{Analysis}

(1) Fire Retardant Evaluation Method. Limiting oxygen index (LOI) according to JIS K720 standard (Japan): the sample bars used for the test were $150 \times 6.5 \times 3 \mathrm{~mm}^{3}$. The average values of the five specimens were reported. The horizontal burning tests (UL-94HB): standard bar specimens are to be $125 \pm 5 \mathrm{~mm}$ long by $13.0 \pm 0.5 \mathrm{~mm}$ wide and provided in the minimum thickness and $3.0(-0.0+0.2) \mathrm{mm}$ thick (ASTM D635-12). The average values of the five specimens were reported.

The UL 94 flame retardant and oxygen limit tests are conducted at the Polymer Materials Research Center-Hanoi University of Technology, Vietnam.

(2) Method for Determining Mechanical Properties. Tensile strength was determined according to ISO 527-1993 standard on INSTRON 5582-100 kN machine (USA) with tensile speed $5 \mathrm{~mm} / \mathrm{min}$, temperature $25^{\circ} \mathrm{C}$, and humidity $75 \%$. The average 


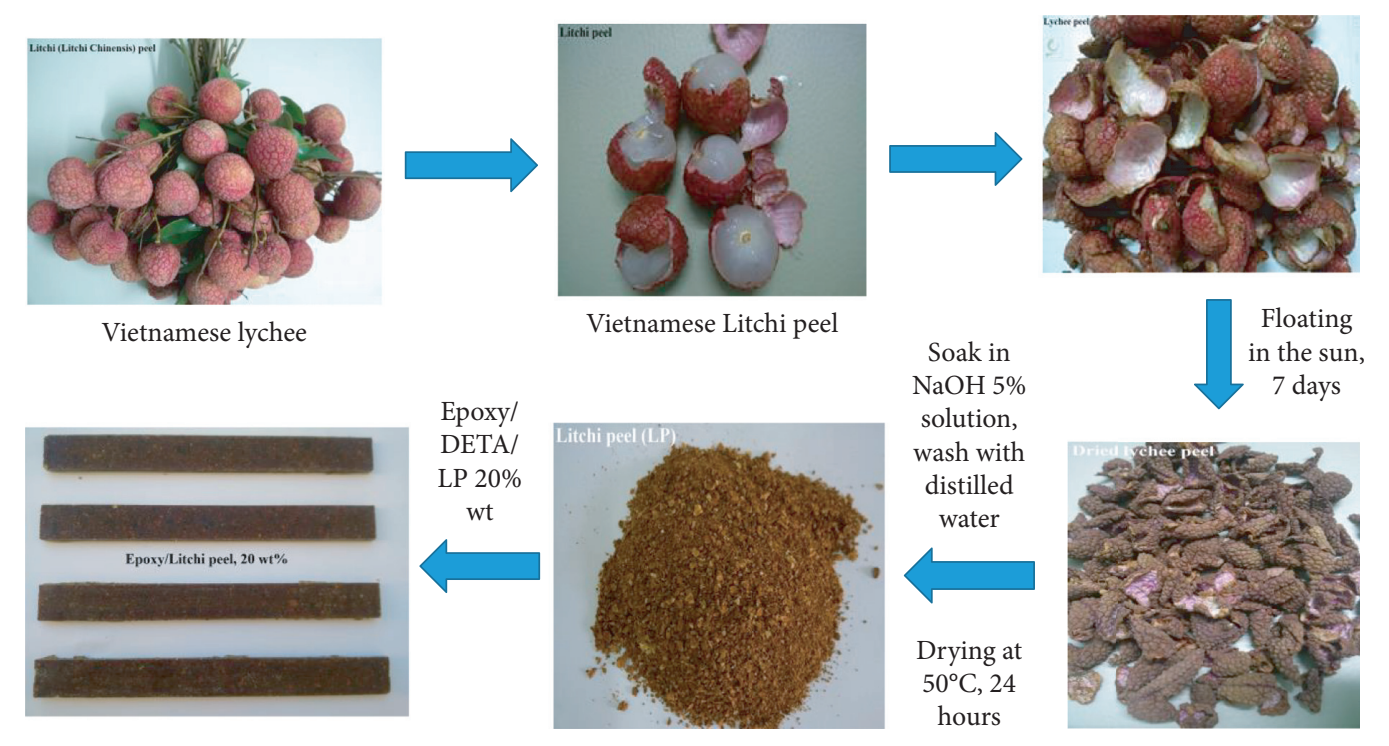

Figure 1: Retreatment process of litchi peel (LP).

values of the five specimens were reported. The flexural strength was determined according to ISO 178-1993 on an INSTRON $5582-100 \mathrm{kN}$ machine (USA) with bending speed of $5 \mathrm{~mm} / \mathrm{min}$, temperature of $25^{\circ} \mathrm{C}$, and humidity of $75 \%$. The average values of the five specimens were reported. Compressive strength was determined according to ISO 604-1993 standard on INSTRON $5582-100 \mathrm{kN}$ machine (USA), compression speed $5 \mathrm{~mm} / \mathrm{min}$, and temperature $25^{\circ} \mathrm{C}$. The average values of the five specimens were reported. Izod impact strength was determined according to ASTM D265 standard on Tinius Olsen machine (USA), measured at Research Center for Polymer Materials, Hanoi University of Science and Technology. The average values of the five specimens were reported. The morphology of the samples was carried out by scanning electron microscope (SEM, SU3800, HITACHI, Japan), measured at Materials Room 1, Faculty of Mechanical Engineering Technology, Hanoi University of Industry, Vietnam.

\section{Results and Discussion}

3.1. Morphology. The structural morphology of the hybrid litchi peel (LP)/epoxy composites was evaluated by SEM and presented in Figure 2. From the microscopic images (Figure 2), it can be seen that the particles are very well distributed in the epoxy resin matrix. Additive particles with different sizes, very good compatibility, and full wetting and full immersion in the epoxy resin mass were observed at the combined ratios. Part of the grain protruding from the surface is due to the material being destroyed by mechanical force (red circle). It was also observed that when the sample was destroyed, the additive particles partially protruded from the surface and on the contact interface between the additive and the epoxy resin matrix, no cracks were found. That shows that the bonding on the surface of phase division between epoxy resin-additives (litchi peel) is very good.

The litchi peel-LP combination ratio of $20 \mathrm{wt} \%$ forms the structural morphology with better adhesion between interfaces than other ratios observed in Figures 2(b) and 2 (d). The surface roughness of the filler is also one of the factors that increase the adhesion of the particles and the substrate. The interlacement between fillers and epoxy resin substrate is also observed in Figure 2(d). The bonding between fillers at a combination ratio of $20 \mathrm{wt} \%$ or more is strong. However, when increasing to $30 \mathrm{wt} \%$ of filler, it is possible that the increased content leads to the formation of a larger agglomerated filler mass, which affects the compatibility and adhesion (see Figure 2(c)). This result is completely consistent with the announcement of Patil et al. [2]. The surface morphology of the sample observed by SEM (Figure 2) indicates that the particles are irregularly shaped, with a rough and porous surface. Therefore, these characteristics are interesting for energy absorption purposes.

3.2. Mechanical Properties. The mechanical properties of epoxy composites reinforced with lychee peel are presented in Figure 3. The results of the mechanical strength test show that, with $20 \mathrm{wt} \%$ lychee peels, higher results were obtained than the combined ratios of $10 \mathrm{wt} \%$ and $30 \mathrm{wt} \%$ as shown in Figure 3.

Results of tensile testing using composite reinforced with $10 \mathrm{wt} \%, 20 \mathrm{wt} \%$, and $30 \mathrm{wt} \%$ lychee peel showed increases compared with primary epoxy materials. The flexural strength of each composite is reported in Figure 2, which is shown to be reduced compared with the primary epoxy material. Similar results have been reported in the literature where, in the presence of additives of natural origin, the flexural strength tends to decrease [2]. For compressive strength and impact strength, Izod increased with the addition of lychee peel.

With the combination of $20 \mathrm{wt} \%$ additive, the tensile strength reached $55.37 \mathrm{MPa}$, flexural strength $72.39 \mathrm{MPa}$, compressive strength $135.37 \mathrm{MPa}$, and Izod impact 


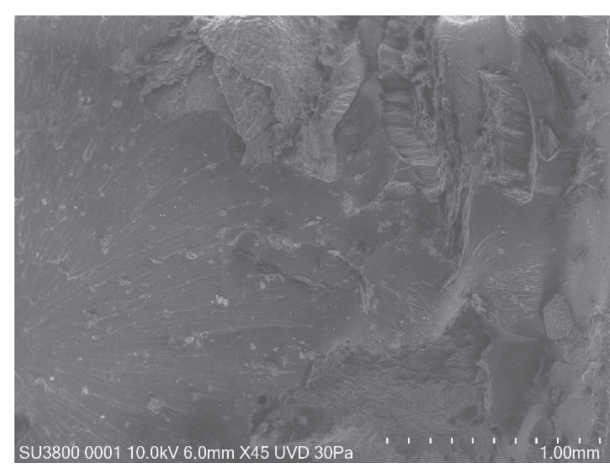

(a)

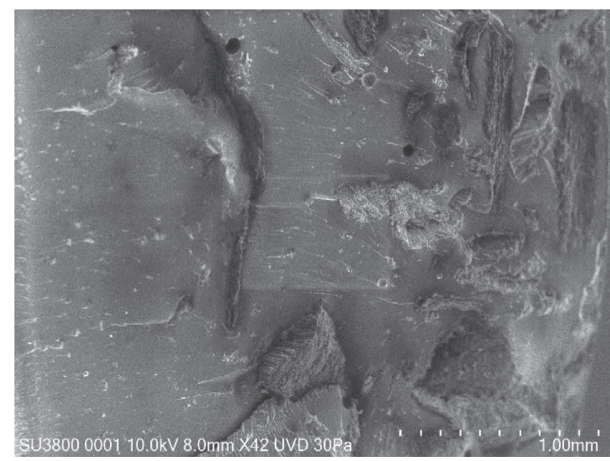

(c)

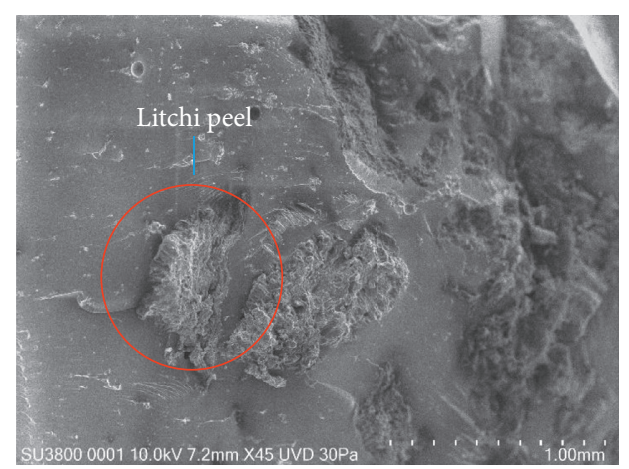

(b)

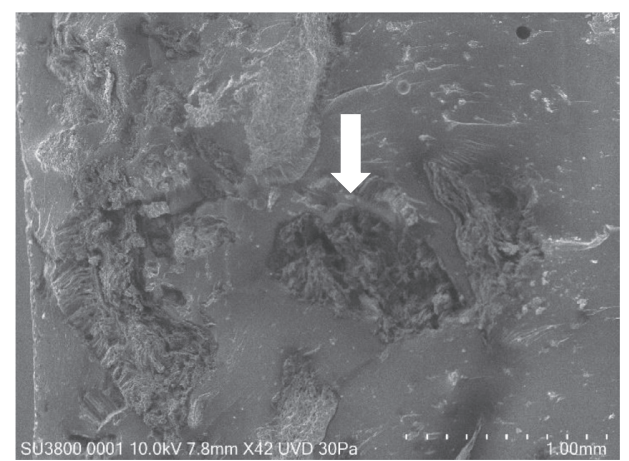

(d)

FIgURE 2: SEM figure of composite/litchi peel (LP): (a) $10 \mathrm{wt} \% \mathrm{LP},(\mathrm{b}, \mathrm{d}) 20 \mathrm{wt} \%$, and (c) $30 \mathrm{wt} \%$.

strength $9.08 \mathrm{~kJ} / \mathrm{m}^{2}$ (see Figure 2). Other combinations of $10 \mathrm{wt} \%$ and $30 \mathrm{wt} \%$ have lower strength values. This result is said to be consistent with the structural morphological features as argued in Figure 2. $20 \mathrm{wt} \%$ mass admixture gives structure with better adhesion and compatibility than the remaining combinations (Figure 2). The increased mechanical properties are attributed to the good compatibility, adhesion, and penetration on interface between epoxy and litchi peel. There are also other factors such as the uniform distribution, the term size, and the nature of the component materials. Figure 2 shows that when increasing to $30 \mathrm{wt} \%$ additive, the strength tends to decrease. This can be explained by the influence of the particle size of the additive because when the concentration increases, it leads to high solution viscosity, lower dispersion, and larger particles caused by agglomeration (Figure 2(c)).

According to Ying Ying Tye et al., the large size of the natural reinforcement will affect the reduction of mechanical strength [28]. According to Ying Ying Tye et al., the micron-sized particle reinforcement for polymer composites has an effect on reducing the mechanical strength of the material. Particle size and mass percent along with surface cohesion play a major role in the resulting mechanical strength results. Figures 4(a) and 4(b)), at two different magnifications and SEM angles, show different details about the fracture surface morphology such as grain distribution in regions, voids (color circle white), and cracks (white arrows). In addition to these factors, particle and substrate adhesion were also observed (white circle,
Figure 4(a)). These properties have influenced the change in mechanical properties.

On the other hand, from Figure 4(a), due to the appearance of additives in the plastic substrate, when the force is applied, the crack's trajectory has been changed (white arrow, Figure 4(a)), the crack direction is changed by the existence of additives. Therefore, the process of destroying the material requires a longer time or a stronger force.

From Figure 5, on the interface between the additive, epoxy resin, it is observed that the compatibility is very strong, and the adhesion is large. No phase division, wetting, or penetration of additive particles was observed at a high threshold (white circle, Figure 5(b)).

The interweaving between additive particles and epoxy resin is at a high level $[2,29]$. On the other hand, when taking SEM at a different angle, the crack formation was observed. However, it is clear that the crack growth path was prevented or changed in the presence of additive particles in the epoxy matrix (see Figure 5(a), white arrow). The fracture surface structure morphology of the material explains the good compatibility of the two-component materials. This is one of the factors affecting the mechanical properties of materials. The structural morphology results are consistent with the mechanical strength.

3.3. Flame Retardant Properties. The major disadvantage of biocomposites is their relatively poor fire resistance [30]. Materials of natural origin are all flammable. They undergo thermal decomposition at low temperatures of 200 to $300^{\circ} \mathrm{C}$ 


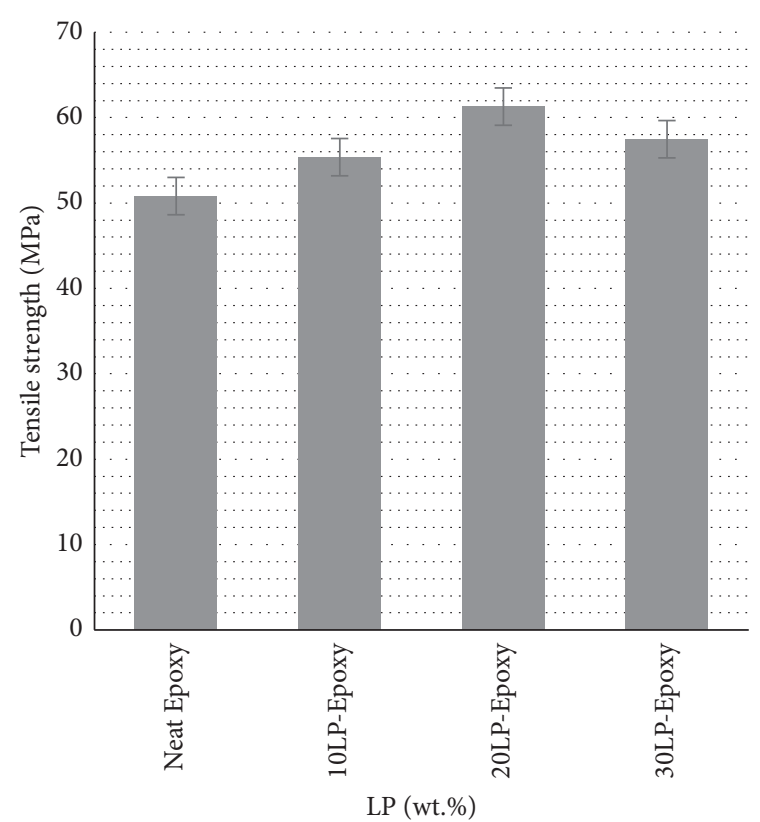

(a)

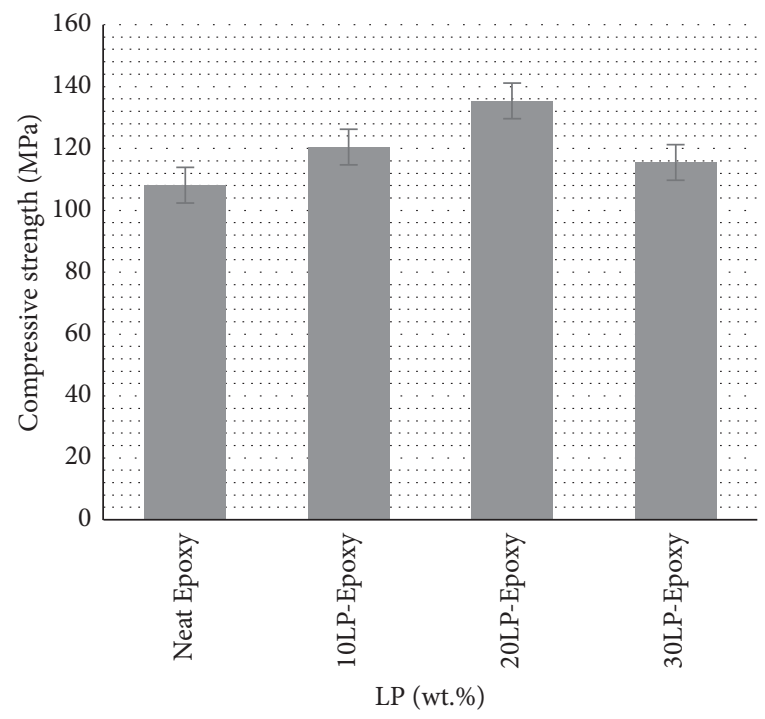

(c)

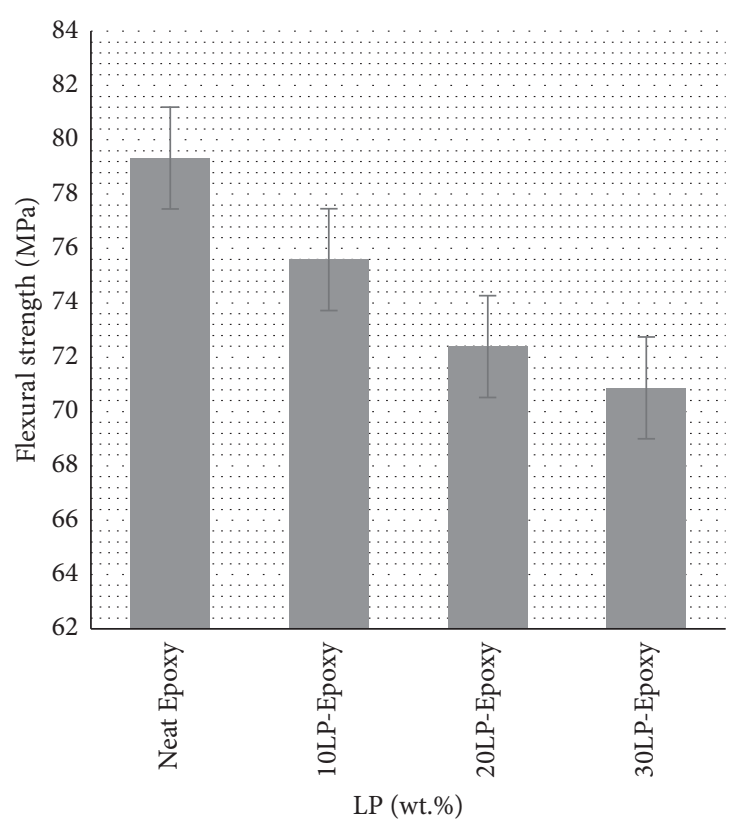

(b)

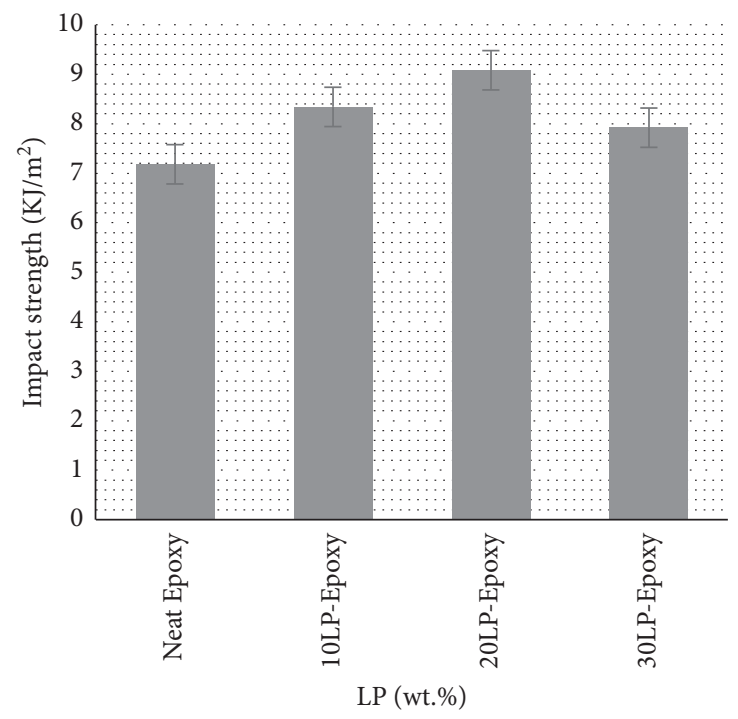

(d)

FIGURE 3: Mechanical properties of epoxy composites reinforced with lychee peels at the following ratios: $0 \mathrm{wt} \% \mathrm{LP}, 10 \mathrm{wt} \% \mathrm{LP}, 20 \mathrm{wt} \%$, and $30 \mathrm{wt} \% \mathrm{LP}$.

[31, 32]. Because of its flammability, it will limit the application of the material in industrial fields. It is important to adapt materials with higher fire resistance without affecting their good mechanical properties [33]. The main function of a carbon-based filler is to form a protective layer of coal during the process of pyrolysis of polymers to limit the transfer of combustible gases and heat and thus do prevent further deterioration of the material [34]. This carbon-rich material has recently been used as a reinforcing agent in polymer composites and leads the way for the production of environmentally friendly composite mechanical properties and fire resistance. Instead of using organic waste directly in the production process biomaterial, biocarbon (BC) is derived from different biomass, such as rice husk, bamboo, grass, and sawdust pine wood.

In this work, the effect of agricultural by-products (lychee peel) on the fire resistance of epoxy composites was studied. The results are presented as shown in Figures 6 and 7.

From the results of Figure 6 on the flame retardant properties, it is shown that when combining the lychee peel additive at different weight percentages into the epoxy resin base, the flame retardant properties tend to be significantly improved. The combination gives high flame retardant properties and reaches the specified threshold of $20 \mathrm{wt} \%$ lychee 


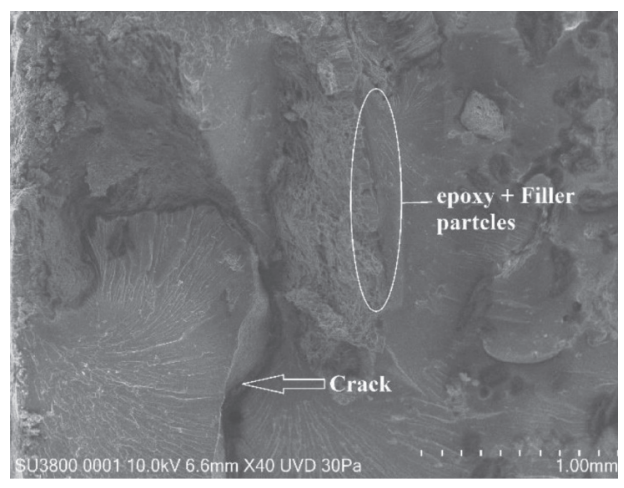

(a)

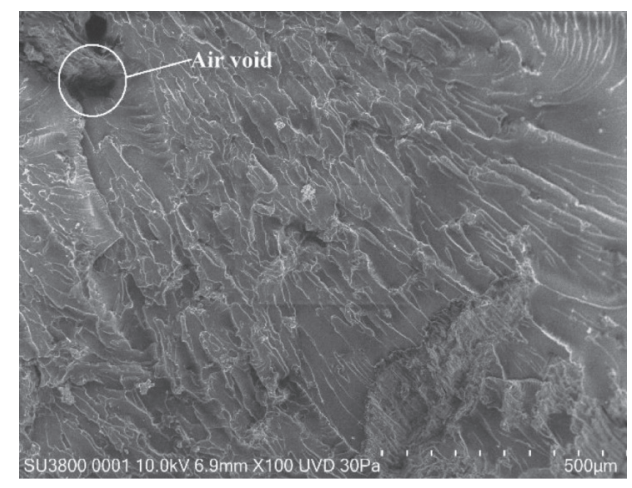

(b)

FIGURE 4: SEM image of broken surface of epoxy composite sample/litchi peel (20 wt\%).

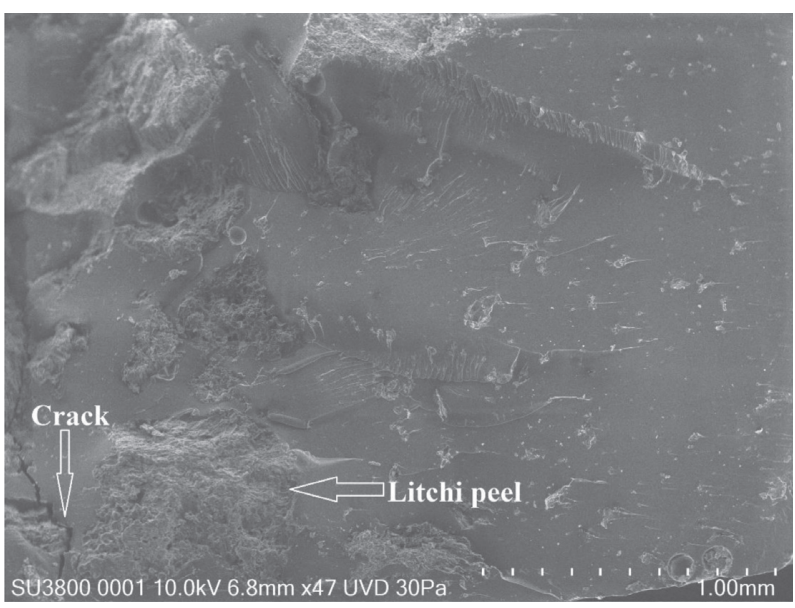

(a)

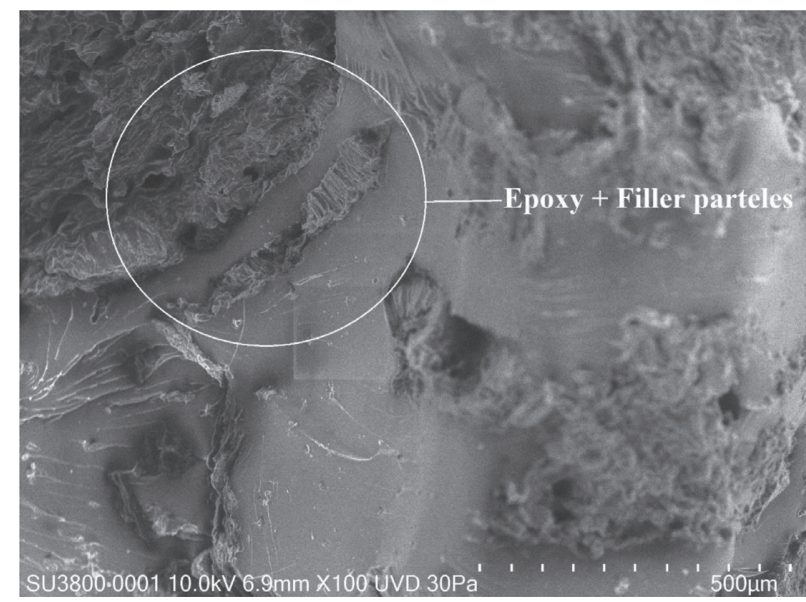

(b)

FIGURE 5: SEM image of broken surface of epoxy composite, $20 \mathrm{wt} \%$ of litchi peel at different magnifications.
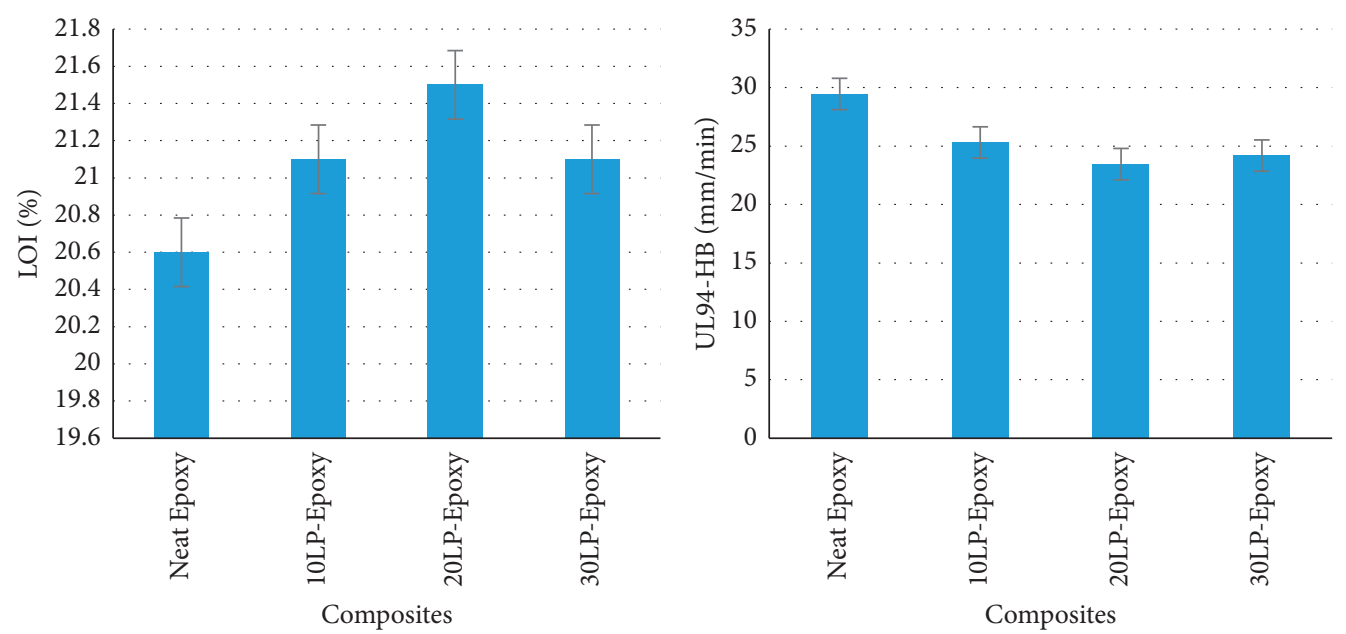

FIGURE 6: Flame retardant properties of epoxy composites reinforced with litchi peel (LP).

rind with a limiting oxygen index of $21.5 \%$; the burning rate according to UL94-HB reaches $23.45 \mathrm{~mm} / \mathrm{min}$.

Additives lychee peel is a rich source of carbon-rich biomass, a by-product from the food industry. When burned, a cinder block is formed and it is possible that it is a form of biochar (BC) (see Figure 7). The surface has a porous honeycomb structure consisting of a high carbon concentration.

BC filler's honeycomb porous structure allows penetration of molten polymers during processing and they create a physical bond, which can lead to improved 

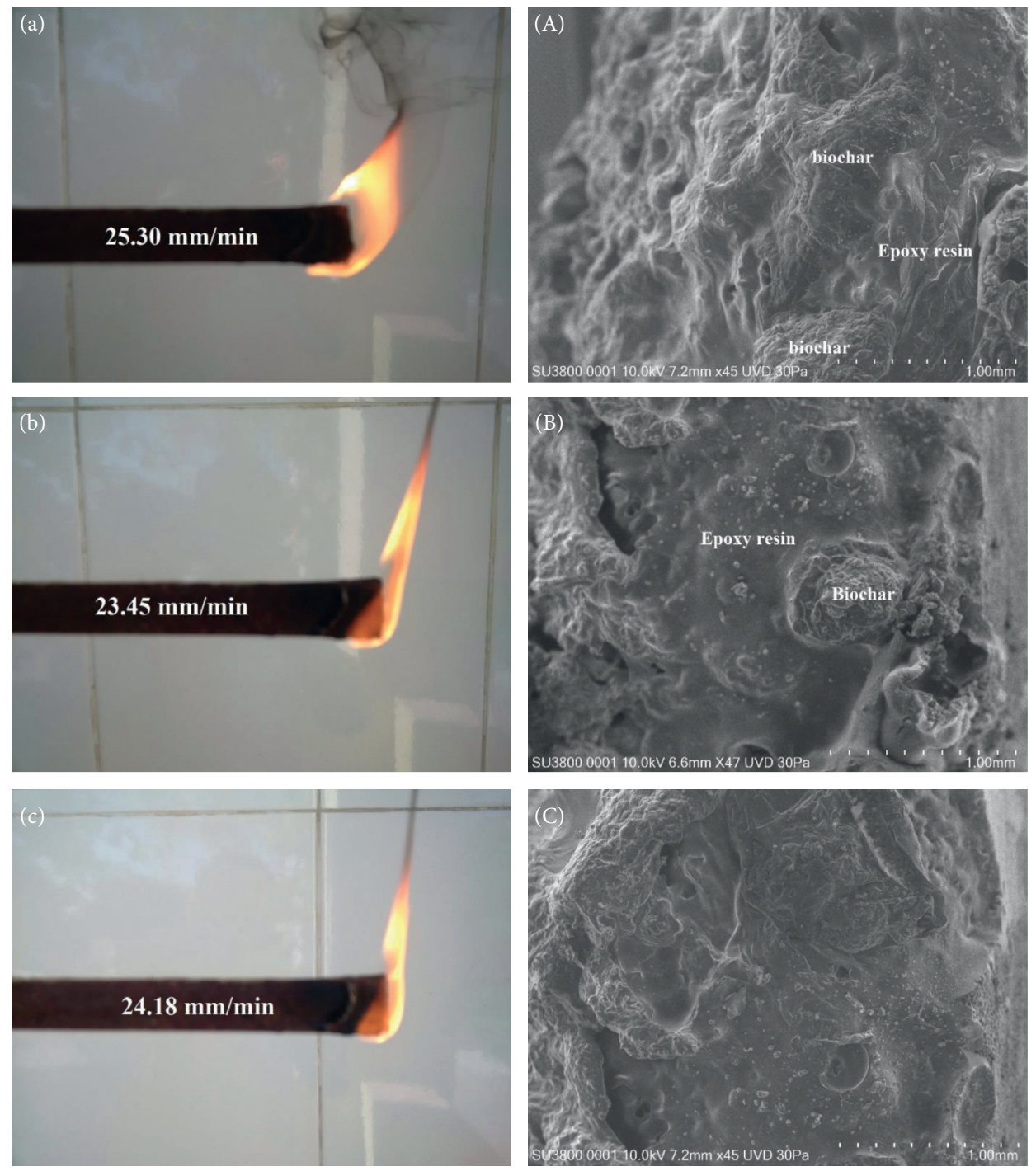

Figure 7: UL94-HB test image and SEM surface image after burning: (A, a) $10 \mathrm{wt} \%,(\mathrm{~B}, \mathrm{~b}): 20 \mathrm{wt} \%$, and (C, c) $30 \mathrm{wt} \%$ litchi peel.

mechanical fit and fire resistance [34, 35]. About the fireproof mechanism of the lychee peel, when burned, the lychee peel forms carbon-rich layers of charcoal and acts as heat-stable films. This film has limited the transport of fuel and $\mathrm{O}_{2}$, leading to improved combustion characteristics, such as limiting oxygen index and burning rate (see Figure 7). In short, carbonbased fillers actively reduce the flammability of polymer composites by (1) forming a protective charcoal layer and (2) absorbing free radicals. The fire resistance of reinforcing materials derived from organic agricultural residues depends on their compatibility with the base material. On the interface between the natural reinforcing agent and the base resin with a compatible structure, good adhesion and good wetting will lead to improved mechanical properties and fire resistance [36, 37].

\section{Conclusions}

In this investigation, the development of a biocomposite material to strengthen lychee peel was established and completed. Litchi pods were combined following ratios of
$10 \mathrm{wt} \%, 20 \mathrm{wt} \%$, and $30 \mathrm{wt} \%$. The following conclusions are drawn from the current investigation:

(i) With a composite rate of $20 \%$ by weight of the lychee peel, the mechanical parameters reached the specified level, increasing compared to monolithic epoxy materials and other combined ratios (10 $\mathrm{wt} \%$; $30 \mathrm{wt} \%)$. The following mechanical properties were observed: tensile strength reached $55.37 \mathrm{MPa}$, flexural strength $72.39 \mathrm{MPa}$, compressive strength $135.37 \mathrm{MPa}$, and Izod impact strength $9.08 \mathrm{~kJ} / \mathrm{m}^{2}$.

(ii) In terms of flame retardant properties, with a combination of different mass percent, $10 \mathrm{wt} \%, 20$ $\mathrm{wt} \%$, and $30 \mathrm{wt} \%$ lychee peel, flame retardant properties (limited oxygen index and burning rate according to UL94-HB) increase, in which the combination of $20 \mathrm{wt} \%$ lychee pods has a limited oxygen index of $21.5 \%$ and a flame retardant rate of $23.45 \mathrm{~mm} / \mathrm{min}$. This ratio is the best compared to the rest of the combinations. 
(iii) The surface morphology of the SEM images revealed that the lychee peel was compatible and adhered to the epoxy resin to a high degree.

Research results in this work once again confirm that the reuse of organic agricultural by-products in the manufacture of composite materials is promising, opening a future trend of making eco-friendly materials.

\section{Data Availability}

All the datasets generated or analyzed during this study are included in this manuscript.

\section{Conflicts of Interest}

The authors declare that there are no conflicts of interest regarding the publication of this paper.

\section{Acknowledgments}

The authors wish to acknowledge the Faculty of Chemical Technology, Hanoi University of Industry, Vietnam, for funding this work.

\section{References}

[1] A. Y. Patil, N. U. Hrishikesh, G. D. Basavaraj, G. R. Chalageri, and K. G. Kodancha, "Influence of bio-degradable natural fiber embedded in polymer matrix," Materials Today: Proceedings, vol. 5, no. 2, pp. 7532-7540, 2018.

[2] A. Y. Patil, N. R. Banapurmath, B. B. Kotturshettar et al., "Experimental and simulation studies on waste vegetable peels as bio-composite fillers for light duty applications," Journal of Cleaner Production, vol. 307, Article ID 127113, 2021.

[3] M. Kostag, K. Jedvert, O. A. El Seoud, and E. Seoud, "Engineering of sustainable biomaterial composites from cellulose and silk fibroin: fundamentals and applications," International Journal of Biological Macromolecules, vol. 167, pp. 687-718, 2021.

[4] S. Niyasom and N. Tangboriboon, "Development of biomaterial fillers using eggshells, water hyacinth fibers, and banana fibers for green concrete construction," Construction and Building Materials, vol. 283, Article ID 122627, 2021.

[5] R. Foroutan, S. J. Peighambardoust, S. S. Hosseini, A. Akbari, and B. Ramavandi, "Hydroxyapatite biomaterial production from chicken (femur and beak) and fishbone waste through a chemical less method for $\mathrm{Cd} 2+$ removal from shipbuilding wastewater," Journal of Hazardous Materials, vol. 413, Article ID 125428, 2021.

[6] T. Gurunathan, S. Mohanty, and S. K. Nayak, "A review of the recent developments in biocomposites based on natural fibres and their application perspectives," Composites Part A: Applied Science and Manufacturing, vol. 77, pp. 1-25, 2015.

[7] S. Li, C. Shi, S. Sun et al., "From brown to colored: polylactic acid composite with micro/nano-structured white spent coffee grounds for three-dimensional printing," International Journal of Biological Macromolecules, vol. 174, pp. 300-308, 2021.

[8] M. Saberian, J. Li, A. Donnoli et al., "Recycling of spent coffee grounds in construction materials: a review," Journal of Cleaner Production, vol. 289, Article ID 125837, 2021.
[9] S. Parbin, N. K. Waghmare, S. K. Singh, and S. Khan, "Mechanical properties of natural fiber reinforced epoxy composites: a review," Procedia Computer Science, vol. 152, pp. 375-379, 2019.

[10] V. Mittal, R. Saini, and S. Sinha, "Natural fiber-mediated epoxy composites-a review," Composites Part B: Engineering, vol. 99, pp. 425-435, 2016.

[11] M. Torres-Arellano, R.-R. Victoria, and F.-U. Edgar, "Mechanical properties of natural-fiber-reinforced biobased epoxy resins manufactured by resin infusion process," Polymers, vol. 12, no. 12, pp. 1-17, 2020.

[12] A. Atmakuri, A. Palevicius, M. Siddabathula, A. Vilkauskas, and G. Janusas, "Analysis of mechanical and wettability properties of natural fiber-reinforced epoxy hybrid composites," Polymers, vol. 12, no. 2827, pp. 1-15, 2020.

[13] G. Rajeshkumar, V. Hariharan, T. P. Sathishkuma, V. Fiore, and T. Scalici, "Synergistic effect of fiber content and length on mechanical and water absorption behaviors of Phoenix sp. fiber-reinforced epoxy composites," Journal of Industrial Textiles, vol. 47, pp. 1-22, 2016.

[14] S.-Q. Chen, P. Lopez-Sanchez, D. Wang, D. Mikkelsen, and M. J. Gidley, "Mechanical properties of bacterial cellulose synthesised by diverse strains of the genus Komagataeibacter," Food Hydrocolloids, vol. 81, pp. 87-95, 2018.

[15] S. Ye, L. Jiang, C. Su, Z. Zhu, Y. Wen, and W. Shao, "Development of gelatin/bacterial cellulose composite sponges as potential natural wound dressings," International Journal of Biological Macromolecules, vol. 133, pp. 148-155, 2019.

[16] P. Choudhary, A. Jaiswal, S. Singh, and S. K. Gupta, "Bacterial cellulose based composites: preparation and characterization," Materials Science Forum, vol. 978, pp. 183-190, 2020.

[17] Z. Rao, H. Ge, L. Liu et al., "Carboxymethyl cellulose modified graphene oxide as $\mathrm{pH}$-sensitive drug delivery system," International Journal of Biological Macromolecules, vol. 107, pp. 1184-1192, 2018.

[18] X. Lu, H. Zhang, Y. Li, and Q. Huang, "Fabrication of milled cellulose particles-stabilized pickering emulsions," Food $\mathrm{Hy}$ drocolloids, vol. 77, pp. 27-435, 2018.

[19] T. A. Nguyen, T. M. H. Pham, T. H. Dang, T. H. Do, and Q. T. Nguyen, "Study on mechanical properties and fire resistance of epoxy nanocomposite reinforced with environmentally friendly additive: nanoclay I.30E," Journal of Chemistry, vol. 2020, Article ID 3460645, 13 pages, 2020.

[20] T. A. Nguyen, "Study on the synergies of nanoclay and MWCNTs to the flame retardant and mechanical properties of epoxy nanocomposites," Journal of Nanomaterials, vol. 2021, Article ID 5536676, 8 pages, 2021.

[21] T. A. Nguyen, Q. T. Nguyen, and T. P. Bach, "Mechanical properties and flame retardancy of epoxy resin/nanoclay/ multiwalled carbon nanotube nanocomposites," Journal of Chemistry, vol. 2019, Article ID 3105205, 9 pages, 2019.

[22] T. A. Nguyen, Q. T. Nguyen, X. C. Nguyen, and V. H. Nguyen, "Study on fire resistance ability and mechanical properties of composites based on Epikote 240 Epoxy Resin and thermoelectric fly ash: an ecofriendly additive," Journal of Chemistry, vol. 2019, Article ID 2635231, 8 pages, 2019.

[23] T. A. Nguyen, "Effects of the amount of fly ash modified by stearic acid compound on mechanical properties, flame retardant ability, and structure of the composites," International Journal of Chemical Engineering, vol. 2020, Article ID 2079189, 6 pages, 2020.

[24] T. A. Nguyen and Q. T. Nguyen, "Study on synergies of fly ash with multiwall carbon nanotubes in manufacturing fire 
retardant epoxy nanocomposite," Journal of Chemistry, vol. 2020, Article ID 6062128, 9 pages, 2020.

[25] T. A. Nguyen and H. P. Thi Mai, "Study on the properties of epoxy composites using fly ash as an additive in the presence of nanoclay: mechanical properties, flame retardants, and dielectric properties," Journal of Chemistry, vol. 2020, Article ID 8854515, 11 pages, 2020.

[26] T. A. Nguyen, "Mechanical and flame-retardant properties of nanocomposite based on epoxy resin combined with epoxidized linseed oil, which has the presence of nanoclay and MWCNTs," Journal of Chemistry, vol. 2020, Article ID 2353827, 8 pages, 2020.

[27] K. P. Ashik and R. S. Sharma, "A review on mechanical properties of natural fiber reinforced hybrid polymer composites," Journal of Minerals and Materials Characterization and Engineering, vol. 3, no. 5, pp. 420-426, 2015.

[28] Y. Y. Tye, K. T. Lee, W. N. Wan Abdullah, and C. P. Leh, "Potential of Ceiba pentandra (L.) Gaertn. (kapok fiber) as a resource for second generation bioethanol: effect of various simple pretreatment methods on sugar production," Bioresource Technology, vol. 116, pp. 536-539, 2012.

[29] R. Badrinath and T. Senthilvelan, "Comparative investigation on mechanical properties of banana and sisal reinforced polymer based composites," Procedia Materials Science, vol. 5, pp. 2263-2272, 2014.

[30] M. Bahrami, J. Abenojar, and M. Á. Martínez, "Recent progress in hybrid biocomposites: mechanical properties, water absorption, and flame retardancy," Materials, vol. 13, no. 22, pp. 1-46, 2020.

[31] M. W. Chai, S. Bickerton, D. Bhattacharyya, and R. Das, "Influence of natural fibre reinforcements on the flammability of bio-derived composite materials," Composites Part B: Engineering, vol. 43, no. 7, pp. 2867-2874, 2012.

[32] O. Das, N. K. Kim, A. K. Sarmah, and D. Bhattacharyya, "Development of waste based biochar/wool hybrid biocomposites: flammability characteristics and mechanical properties," Journal of Cleaner Production, vol. 144, pp. 79-89, 2017.

[33] M. Mochane, T. C. Mokhena, T. Mokhothu et al., "Recent progress on natural fiber hybrid composites for advanced applications: a review," General Science And Engineering Technologies, vol. 13, 2019.

[34] K. Babu, G. Rendén, R. Afriyie Mensah et al., "A review on the flammability properties of carbon-based polymeric composites: state-of-the-art and future trends," Polymers, vol. 12, no. $1518,2020$.

[35] R. Ortega, M. D. Monzón, Z. C. Ortega, and E. Cunningham, "Study and fire test of banana fibre reinforced composites with flame retardance properties," Open Chemistry, vol. 18, no. 1, pp. 275-286, 2020.

[36] T. A. Nguyen and T. H. Nguyen, "Banana fiber-reinforced epoxy composites: mechanical properties and fire retardancy," International Journal of Chemical Engineering, vol. 2021, Article ID 1973644, 9 pages, 2021.

[37] T. A. Nguyen and Q. T. Nguyen, "Hybrid biocomposites based on used coffee grounds and epoxy resin: mechanical properties and fire resistance," International Journal of Chemical Engineering, vol. 2021, Article ID 1919344, 12 pages, 2021. 